\title{
INJECTION MOLDING SimUlations OF HARDLY Producible PARTS From PBT
}

\author{
Karel Raz, Martin Zahalka \& Roman Polak
}
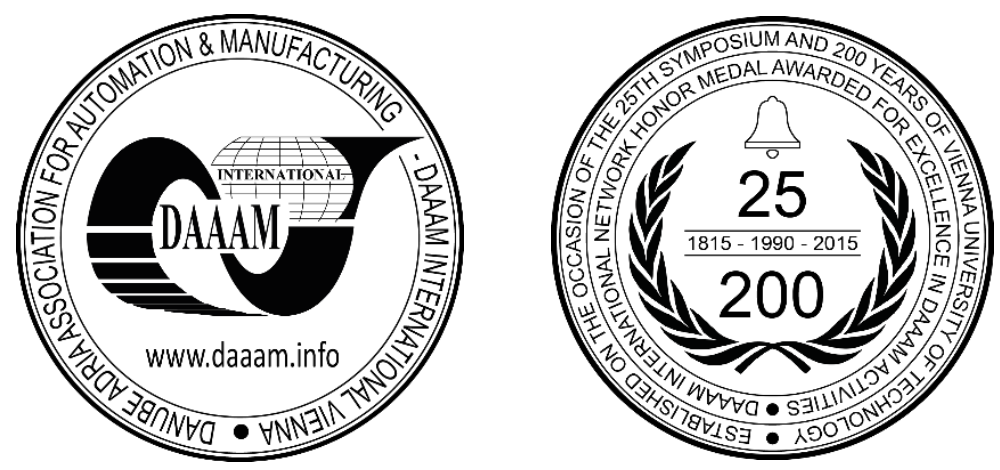

This Publication has to be referred as: Raz, K[arel]; Zahalka, M[artin] \& Polak, R[oman] (2016). Injection Molding Simulations of Hardly Producible Parts from PBT, Proceedings of the 27th DAAAM International Symposium, pp.05010505, B. Katalinic (Ed.), Published by DAAAM International, ISBN 978-3-902734-08-2, ISSN 1726-9679, Vienna, Austria

DOI: $10.2507 / 27$ th.daaam.proceedings.075

\begin{abstract}
This article is focused on possibilities of advanced injection molding simulations. Parts made from plastic materials are in almost all technical systems. A lot of various hardly producible plastic parts are used nowadays. Examples are components of electronical systems, mainly various connectors from material polybutylene terephthalate (PBT). These connectors are long in one direction and their geometry is with high number of various small holes. This leads to problems during injection molding. Movement of melted plastic material is slow and also number of weld lines is high. Main aim of this article is comparing of different variants of injection molding process and demonstration of CAE advanced methods usage. This approach leads to optimized production of plastic connectors. During simulation is used accurate material model of PBT which is clearly described.

Results leads to mathematical description of dependence between all injection molding parameters and results from this technological process. Mainly are described temperatures and pressures in various moments of injection process. Results of research describe all influences on quality of product. This is done by evaluation of geometrical, optical and mechanical properties of final connector. As an example is used connector with 54 independent contacts. Validation of simulation is performed by comparing with real experiment.
\end{abstract}

Keywords: injection molding; PBT; virtual simulation; surface quality; connector.

\section{Introduction}

Nowadays are really often used parts made from plastic materials. Their market share is rapidly increasing. In all areas of engineering are still produced parts with more complex shapes. It is necessary to shorten time when new product is started to be produced. It is suitable to used modern mold-flow analysis. This kind of analysis is able to show weak points of process and it is possible to optimize it virtually without stopping production line. Connector for electronic industry is chosen as an example (according Fig. 1). The filling of this part is only from one side. This leads to problematic mold filling. This part is also suitable for optimization. Final product should be with better properties and more reliable molding process. $[8,9,10]$

Our research shows how can be injection molding process optimized with mold flow analysis and how can be described material for this kind of analysis. 


\section{Simulation model}

Simulation model is clearly described in Fig.1. For simulation is critical parameter diameter of entrance gate, which is here $1.3 \mathrm{~mm}$. Design of mold is also obvious in Fig.1 (right). There is visible shape of cooling channels. For this kind of virtual simulation is not necessary to model each body of mold cores. We are interested here in cavity of mold. Whole simulation was performed in system Moldex3D. This software is used for advanced simulation of injection molding. 3D design of CAD parts was performed in Siemens NX10 software with usage of exporting data into Moldex 3D. [4,5]
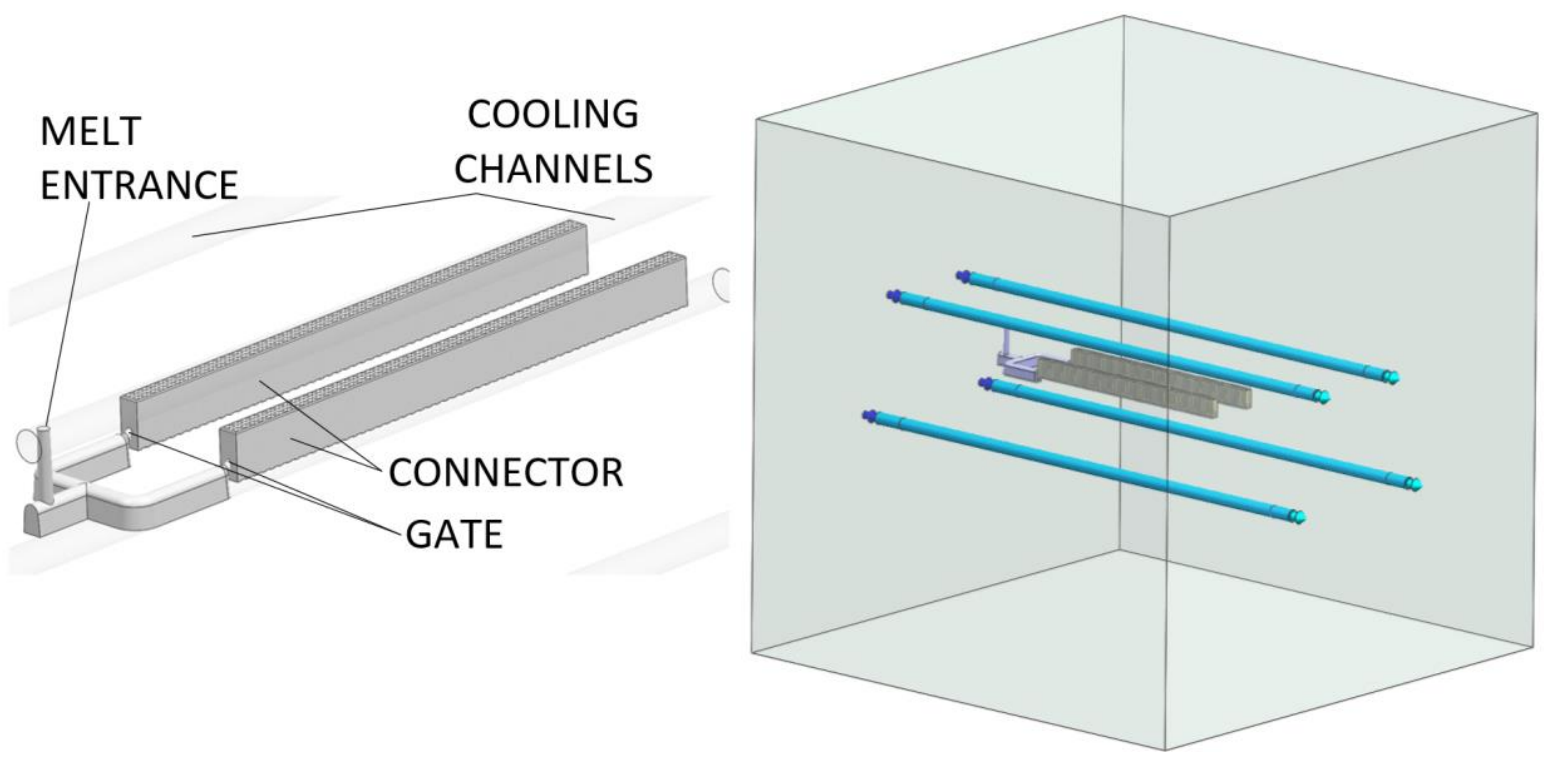

Fig. 1. Detail of cavity filled by plastic material with two connectors and mold design

\section{Material model for virtual simulation}

Material CELANEX 3316 was used for simulation. It is PBT (polybutylene terephthalate) with 30\% of glass fibres. These properties are exactly according material list given by producer Celanese. All these properties are essential for correct results and have to be used as one of inputs for finite element solver [6,7].

One of the most important parameters for molding analysis is viscosity. This parameter is highly dependent on temperature and shear rate. In following graph (Fig.2 left) is visible, how is during simulation viscosity changed comparing to temperature and shear rate. In case that during injection molding is problem with filling of cavity, this problem can be solved by higher viscosity of material. As is visible from following graph, viscosity is changed more with shear rate than with temperature (in comparable ranges). Influence of temperature and pressure on specific volume of part has to be also considered in simulation. In general, this relation can be described in Fig. 2 right.
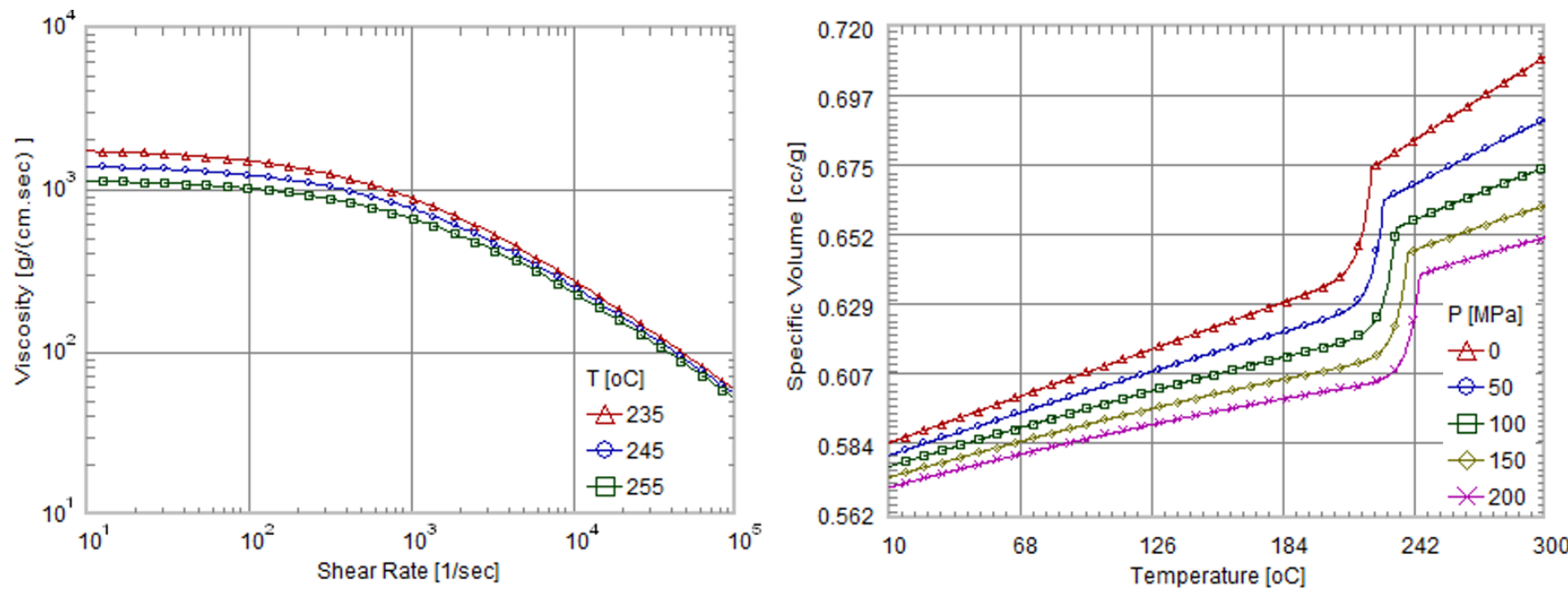

Fig. 2. Description of viscosity (left) and specific volume (right) 


\section{Simulation of injection molding}

First set of parameters is all the time hard to predict. Designer is able to make some iterations with using of virtual simulation for getting more suitable parameters. As first entering parameters were chosen following:

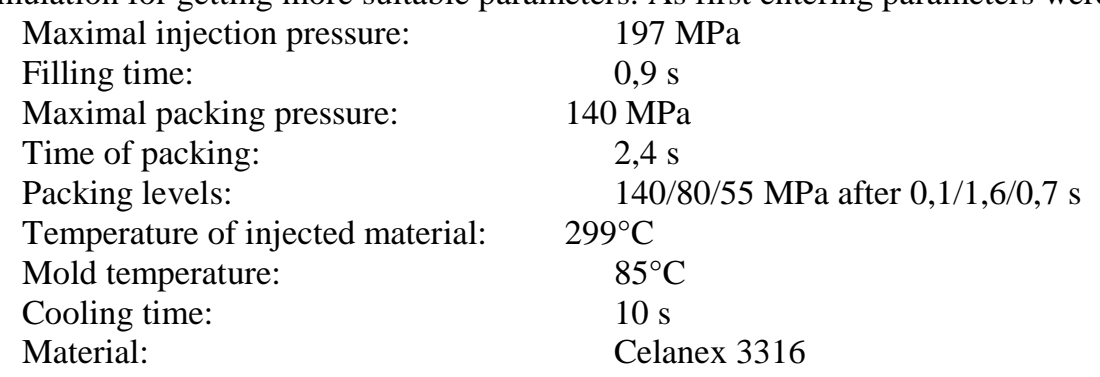

First problem is obvious from selected parameters. Because is chosen part with filling only from one side, it is necessary to have maximal temperature of molded material. It was chosen temperature $299^{\circ} \mathrm{C}$, which is still material able to survive. Whole process has to be controlled in terms of maximal shear stress (not above $500001 / \mathrm{s}$ ) because higher stress can lead to increasing of temperature in entrance gates and to destroying of material. [3,4]

\subsection{Filling results}

Filling time is achieved and parts are fully filled as is obvious in Fig.3. The maximal permissible injection pressure wasn't achieved during process. So as a result from filling is visible, that time may be shorter, because maximal injection pressure is not limiting actual pressure.

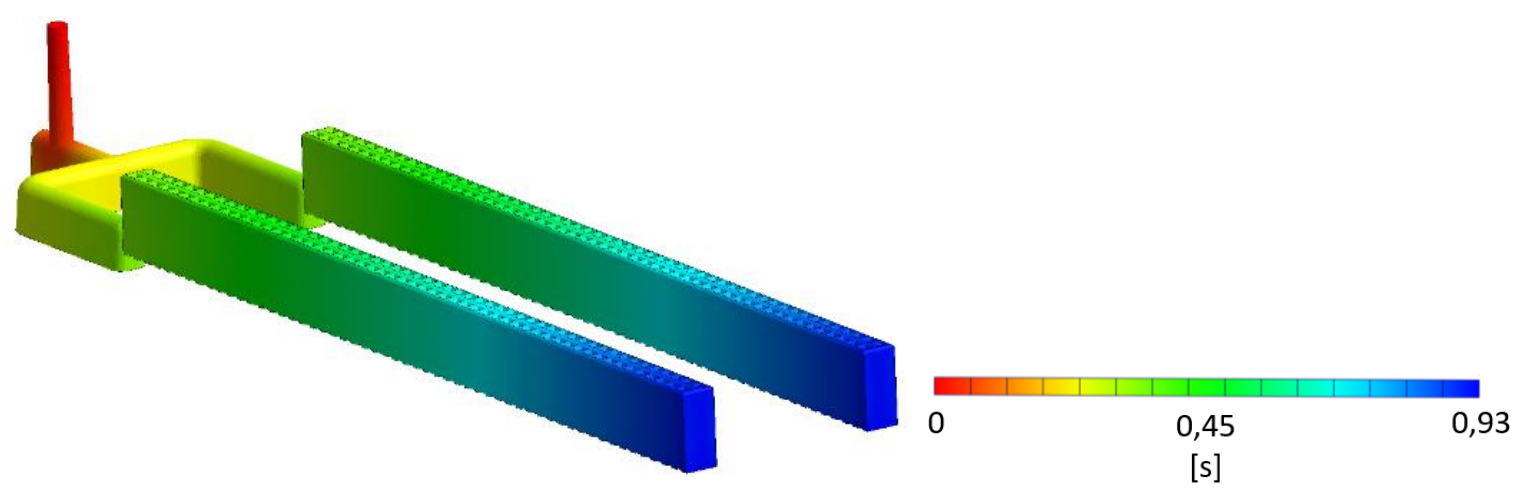

Fig. 3. Filling time

Temperature at the end of filling stage is sufficient close to the gates as is visible in Fig.4. But is obvious that in the middle of part is temperature under $200^{\circ} \mathrm{C}$ and material is there in solid state. This happened in areas close to shaped cores for holes and generally for areas which are in contact with material of mold.

As far from gate is temperature evaluated as lower is. This leads to decreasing of viscosity and problems with filling.

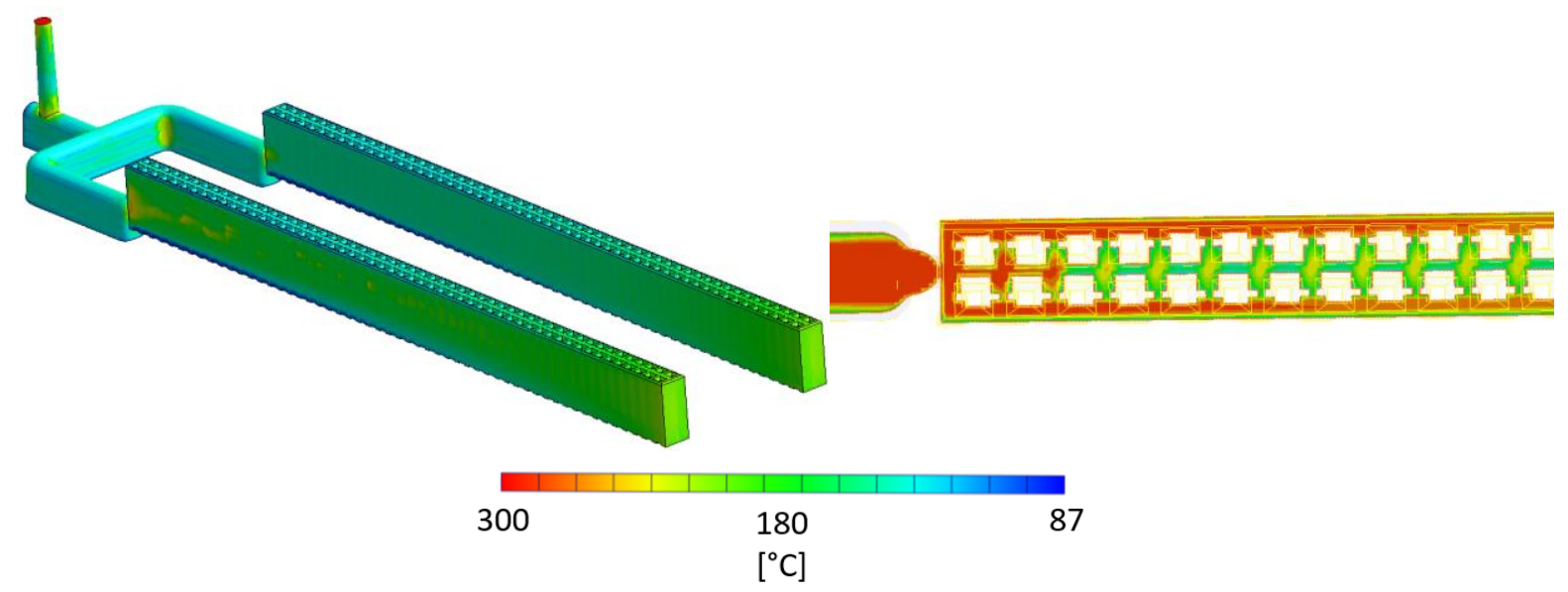

Fig. 4. Temperature at the end of filling- general view and cut 


\subsection{Packing results}

Temperature at the end of packing is in Fig.5. It is visible that material is almost everywhere in solid state and can be ejected from mold.

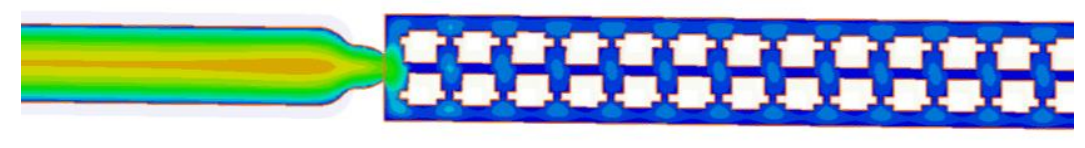

Fig. 5. Temperature at the end of packing stage

It is possible to show shape of non-solid material as interesting result. Product is in solid state at the end of packing really and can be ejected. It is visible in Fig.6.

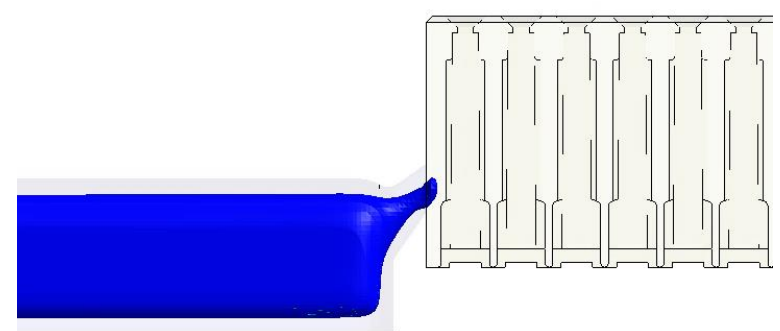

Fig. 6. Non- solid volume of plastic material

\section{Findings from simulation and next steps- optimization}

From performed simulation is obvious that selected parameters of molding process (times and pressures) were chosen quite good. This process can be still optimized. We were focused on maximization of temperature at the end of filling stage. If temperature will be higher, viscosity will be better, part will be filled easier and visual properties will be on higher level.

Technological process was optimized firstly in terms of shortening time of filling stage. The time was decreased from initial $0.9 \mathrm{~s}$ to final $0.25 \mathrm{~s}$. Decreasing of filling time leads to higher production rate in terms of pieces per unit of time.

As is visible in Fig.7, the temperature compared with first process, is on higher level. Generally, it is up to $10 \%$ higher. $[1,2]$

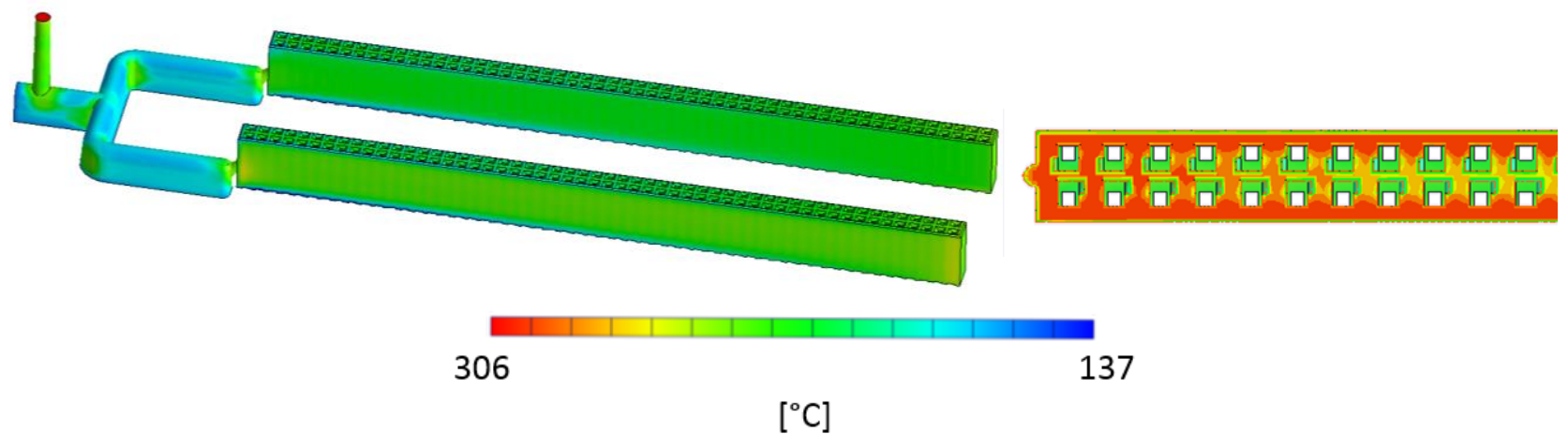

Fig. 7. Temperature at the end of filling after optimization- general view and cut

\section{Discussion}

These optimized parameters were used on real injection molding machine and final product was with all parameters according performed virtual simulation. This approach was used for virtual simulation validation. Comparing of initial setup and optimized setup of molding parameters was performed and temperature is more uniform after optimization. This leads to better optical properties of product and uniform shrinkage. 
Approach of using virtual simulations in iterations leads to optimized production on minimizing of waste times on machines.

\section{Conclusion}

This article shows possibilities and advantages of using virtual mold-flow analysis. Process of determining parameters for injection molding as is shown here can rapidly decrease time, when production line is stopped because of testing new molding process.

Results from this kind of analysis are highly material-dependent, so it is obligatory to set up simulation material according material list of real material. Material model and input data, which are necessary to put into simulation are shown in chapter material model. Parameters from this simulation were used for real experiment on machine and results were comparable with simulation.

\section{Acknowledgments}

The article has been prepared under project LO1502 'Development of the Regional Technological Institute' under the auspices of the National Sustainability Programme I of the Ministry of Education of the Czech Republic aimed to support research, experimental development and innovation.

\section{References}

[1] Popa, C. L.; Parpala, R. C. \& Cotet, C. E.(2012). Contact Identification for Assembly/Disassembly Process in CADCAE Software, Annals of DAAAM for 2012 \& Proceedings of the 23rd International DAAAM Symposium, ISBN 978-3-901509-91-9, ISSN 2304-1382, pp 0613 - 0616, Editor B[ranko] Katalinic, Published by DAAAM International, Vienna, Austria

[2] Chwastyk, P. \& Kolosowski, M.(2012). Integration CAD/CAPP/CAM Systems in Design Process of Innovative Products, Annals of DAAAM for 2012 \& Proceedings of the 23rd International DAAAM Symposium, ISBN 9783-901509-91-9, ISSN 2304-1382, pp 0397 - 0400, Editor B[ranko] Katalinic, Published by DAAAM International, Vienna, Austria

[3] Piscan, I.; Janssens, T. \& Predincea, N. (2011). Experimental Validation of FEM for Frictional Contacts, Annals of DAAAM for 2011 \& Proceedings of the 22nd International DAAAM Symposium, 23-26th November 2011, Vienna, Austria, Volume 22, No. 1, ISSN 1726-9679, ISBN 978-3-901509-83-4, Katalinic, B. (Ed.), pp. 0741-0742, Published by DAAAM International Vienna, Vienna

[4] Opran, C.; Balota, D. A.; Teodorescu, D. F. (2016). Modelling Assisted Injection Molding with Magnetic Field for Complex Polymeric Products, Proceedings of the 26th DAAAM International Symposium, pp.0301-0310, B. Katalinic (Ed.), Published by DAAAM International, ISBN 978-3-902734-07-5, ISSN 1726-9679, Vienna, Austria DOI:10.2507/26th.daaam.proceedings.041

[5] Sabau, A.; Barhalescu, M. L. \& Oanta, E.: Modeling of High-Pressure Fuel Injection Systems, Annals of DAAAM for 2012 \& Proceedings of the 23rd International DAAAM Symposium, ISBN 978-3-901509-91-9, ISSN 23041382, pp 1019 - 1022, Editor B[ranko] Katalinic, Published by DAAAM International, Vienna, Austria, 2012

[6] Stanek, M.; Manas, M.; Manas, D.; Kyas, K.; Navratil, J. \& Senkerik, V. (2011). Injection Molding Process and its Optimization, Annals of DAAAM for 2011 \& Proceedings of the 22nd International DAAAM Symposium, 23-26th November 2011, Vienna, Austria, Volume 22, No. 1, ISSN 1726-9679, ISBN 978-3-901509-83-4, Katalinic, B. (Ed.), pp. 0155-0156, Published by DAAAM International Vienna, Vienna

[7] Kyas, K.; Stanek, M.; Manas, M.; Manas, D.; Navratil, J. \& Senkerik, V. (2011). Influence of Runner System Design on Molding Process, Annals of DAAAM for 2011 \& Proceedings of the 22nd International DAAAM Symposium, 23-26th November 2011, Vienna, Austria, Volume 22, No. 1, ISSN 1726-9679, ISBN 978-3-901509-83-4, Katalinic, B. (Ed.), pp. 0733-0734, Published by DAAAM International Vienna, Vienna

[8] Ausperger, A. (2011). Simulation of Deformation and Compression of Fabric During the Back Injection Moulding Process, Annals of DAAAM for 2011 \& Proceedings of the 22nd International DAAAM Symposium, 23-26th November 2011, Vienna, Austria, Volume 22, No. 1, ISSN 1726-9679, ISBN 978-3-901509-83-4, Katalinic, B. (Ed.), pp. 1261-1262, Published by DAAAM International Vienna, Vienna

[9] Kyas, K.; Stanek, M.; Manas, M.; Manas, D.; Krumal, M. \& Cerny, J. (2010). Polymer Injection Molding Process Simulation, Annals of DAAAM for 2010 \& Proceedings of the 21st International DAAAM Symposium, 20-23rd October 2010, Zadar, Croatia, ISSN 1726-9679, ISBN 978-3-901509-73-5, Katalinic, B. (Ed.), pp. 1081-1082, Published by DAAAM International Vienna, Vienna

[10] Rotar, I. D.; Cosma, C.; Tut, V. \& Serban, I. (2010). Algoritm for Realization of a die used in Micro Injection Molding, Annals of DAAAM for 2010 \& Proceedings of the 21st International DAAAM Symposium, 20-23rd October 2010, Zadar, Croatia, ISSN 1726-9679, ISBN 978-3-901509-73-5, Katalinic, B. (Ed.), pp. 1275-1276, Published by DAAAM International Vienna, Vienna 